BOLETIM DE PESQUISA NELIC: Edição Especial $V^{\circ} 3$ - Dossiê Murilo Mendes

Artigos

\title{
FRAGMENTOS DE TEMPO \\ Ecos Imemoriais
}

Diego Cervelin 
No vocabulário musical, "siciliana" remete a um tipo de ária ou de movimento ins-trumental que teria ganhado força no fim do século XVII, provavelmente relacionada a uma dança mais antiga, meditativa, chamada "La Siciliana". Ela geralmente segue um compasso lento em 6/8 ou 12/8 de ritmos saltitantes, melodias simples e harmonias diretas. Associada, ainda, às cenas pastoris e às emoções melancólicas, a "siciliana" foi muito utilizada nas óperas de Alessandro Scarlatti e de Haendel, e nos concertos de Bach e de Vivaldi. Esses mesmos dicionários nos dizem também que, do século XIV ao início do século XVII, o termo se referia ao canto ou à declamação de uma forma poética conhecida como strambotto siciliano. As explicações que os livros de música nos dão apontam para alguns sintomas que emergem a partir dos treze poemas que Murilo Mendes escreveu, entre 1954 e 1955, durante a sua primeira estadia na Europa e sob a influência de sua visita à Sicilia. Esses treze poemas, cujos títulos comportam alguns significantes caros ao barroco - como "ruínas", "túmulos", "meditação", "marionete”, "eco" - foram publicados em 1959, na Itália, em edição bilíngüe. A apresentação aos poemas foi escrita por Giuseppe Ungaretti que, além de poeta, também foi um dos primeiros tradutores de Mallarmé para o italiano, professor na USP durante a Segunda Guerra e estudioso de Góngora. Não era de causar espanto 
que, no texto que abria os poemas de Murilo Mendes, Ungaretti mencionasse, então, justamente uma das figuras mais caras à poesia gongórica: Polifemo, o primitivo ciclope, filho do deus do mar e de uma ninfa, e que vivia na Sicília pastoreando suas ovelhas quando foi cegado, num ato de astúcia, por Ulisses enquanto procurava seguir o rumo em direção ao seu reino:

O Brasil é um país onde, ainda hoje, o homem vive em contraste com a natureza virgem; é um daqueles países da descoberta da América cujos contrastes com o espírito ocidental contribuíram para sugerir as formas barrocas e tornaram Polifemo popular na poesia de então. Polifemo era a imagem - surgida na Sicília da violência que jamais conseguirá domar a graça. Como se pode ver, na Bahia e em Minas Gerais, o barroco é uma luta mais imediata com o gigante, mais corpo a corpo que em outros momentos da história; mas o homem ainda tentava medir-se e medir o universo com sua própria medida e ainda se dava conta de que no excesso estava a catástrofe, à qual a graça podia opor-se, e de que podia manifestar uma vida jovem, uma beleza perene, mesmo além da morte, dominado o horror ao vazio.

Com uma encantadora surpresa, Murilo Mendes concentra em si mesmo aquele momento antigo da história humana, no qual entendimento, emoção e sentidos encontram seu puro equilíbrio objetivo. Chega a esse ponto, atravessando seu mundo barroco; chega a esse ponto com a angústia que o dilacera, do mesmo modo como dilacera todos os seus contemporâneos.

São essas as razões pelas quais tanto me agradam os versos que a Sicília Ihe inspirou (versos, sem dúvida, como fotos instantâneas), que, entretanto, só poderiam surgir depois de uma experiência profunda e de uma profunda emoção (Ungaretti, 1995, p. 38).

Embora não diga com todas as letras, a apresentação de Ungaretti retoma pelo menos dois pontos que foram analisados por Walter Benjamin em seu estudo sobre o Trauerspiel: o horror vacui e a angústia dilacerante, intimamente relacionados a um corpo a corpo com o tempo, a experiência histórica e a possibilidade de criação. A propósito, na Meditação de Agrigento, podemos ler algo que não se afasta disso:

Transformar-se ou não, eis o problema.

Durar na zona limite da memória,

Nos limbos da vontade,

Ou submeter a pedra, cumprir o ofício rude

Aprender do lavrador e do soldado.

Qual a forma do poeta? Qual seu rito?

Qual sua arquitetura?

(Mendes, 1995, pp. 567-568).

Sob a influência dos humores saturninos ou de uma espécie daquele "sol inverso" que se entrevê na atmosfera dos Túmulos 
Reais que Murilo Mendes encontrou na catedral de Palermo, Benjamin dizia que o melancólico estava constantemente assujeitado a uma hipertrofia da memória que o impedia de agir em seu tempo atual (Benjamin, 1984, p. 169). Ficava, portanto, absorto em suas maquinações, como parte de um mundo em que aquilo que foi já não é mais, entrecortado pela falta de um passado e pela nebulosa sensação de o porvir jamais poder corresponder à expectativa desejada. Seu coração permanecia quase inerte, apegado à ruminação meditativa. Suas alegrias apenas bruxuleavam inscritas na memória e difíceis de apreender com as mãos. Tédio e desânimo, ou tristeza e desespero poderiam ser seus sinônimos, na medida em que sua capacidade para ver invertia-se sobre a catástrofe - que já havia acontecido: as colunas caindo e espalhando-se em pedaços, os utensílios do dia-a-dia atirados ao chão e que, no agora, parecem mais ter a mínima serventia (Benjamin, 1984, p. 164). Até a esperança beatificante de uma vida eterna no além-túmulo não parecia indicar ao melancólico qualquer alento para a inércia de seu coração. Restava, pois, a contemplação da vacuidade de todas as representações circundantes: a caveira, o túmulo, a ruína, a decadência (Benjamin, 1984, p. 162). Mais uma vez, os túmulos reais da catedral de Palermo parecem, pelo menos a princípio, transluzir algo desse sentimento no poema escrito por Murilo Mendes:

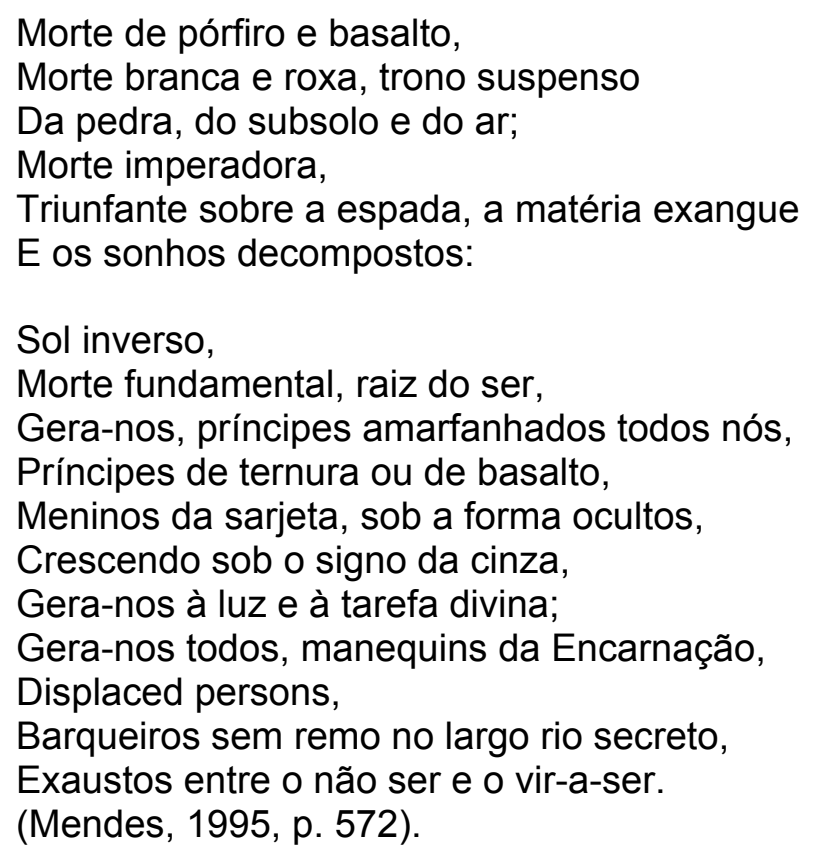

Por outro lado, na releitura que Agamben apresentou em torno do humor melancólico, o instigante estudo Stanze. La parola e il fantasma nella cultura occidentale, aponta para algo, no mínimo, ainda mais fugidio e ainda mais instigante, ou seja, a relação do desejo com seu "objeto". Na compreensão da melancolia estavam em jogo dois elementos persistentes tanto nos estudos feitos pelos Padres da Igreja quanto naquele, Luto e 
melancolia, publicado, em 1917, por Freud: o recesso do "objeto" e o ensimesmamento da intenção contemplativa. No entanto, os estudos de Freud apontavam para certa mistura entre a regressão narcisista e o sentimento de luto. Isso porque, na melancolia, espécie de condição ou sentimento cuja explicação é sempre um tanto quanto embaraçosa, mesmo havendo a manifestação de uma perda do objeto de desejo, não se seguiria a transferência da libido para outro, senão a retração do eu identificado precisamente àquele objeto perdido (Agamben, 2006, p. 24). Assim, enquanto o luto é aquele sentimento que segue a uma perda efetiva, em relação à melancolia, a perda não se apresenta de modo tão claro ou evidente: não se sabe qual objeto foi perdido e nem mesmo se houve de fato uma perda. Nesse sentido, o humor melancólico parece desenvolver uma paradoxal intenção de luto que precede e antecipa a perda mesma do objeto. A acedia - o nome clássico conferido à melancolia - cresce então nos meandros de uma falha que congrega a exacerbação do desejo que torna inacessível o próprio objeto e a tentativa desesperada de esquivar-se da possível perda. Em outros termos, a retração da libido melancólica não teria outro objetivo senão aquele de tornar possível a apropriação de algo naquelas situações em que ela não é efetivamente realizável sem falhas, erros e vácuos. Com isso, a regressão diante da perda do objeto de desejo acaba cedendo espaço à noção de que a melancolia é muito mais a capacidade fantasmática de fazer parecer perdido um objeto do qual não se pode apropriar. E é a partir disso que Agamben aproxima a compreensão da melancolia àquela do fetiche, na medida em que se apresenta como a assinatura de algo e também de sua ausência - o que não se afasta de algo como A marionete de Palermo:

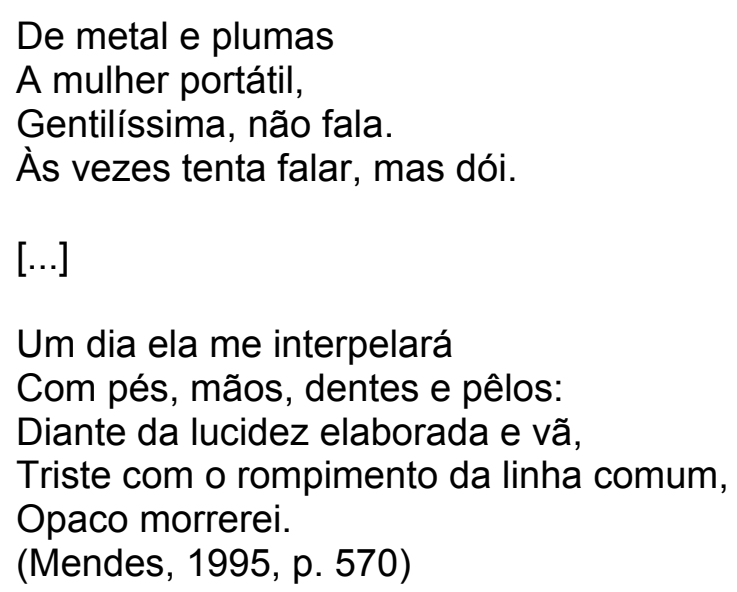

Também aí nos defrontamos com uma situação que confunde real e irreal, incorporado e perdido, afirmado e negado, tal qual Pigmalião diante de sua musa de cera (cf. Agamben, 2006, pp. 25-27). E, não por acaso, uma longa tradição que remonta a Aristóteles, ligava justamente a acedia às 
potencialidades da imaginação. Nesse sentido, a experiência da linguagem tal qual provada pelos poetas do dolce stil novo seria um bom exemplo, com toda a fantasia a respeito do amor pela Musa - e que muito bem poderia servir de outro nome para a paixão do e pelo pensamento. É contando com isso que se pode retornar àquilo que se dizia antes sobre o aspecto musical da siciliana. Porém, não sem fazer mais uma pequena digressão: quando os artistas do renascimento se dispuseram a envolver palácios e catedrais com colunas, frontões e escadarias de mármore, seus modelos poderiam muito bem ter sido recolhidos em Segesta ou Selinunte. Formularam seus cânones sob aquela matéria mineral que restou dos velhos monumentos e propuseram, finalmente, o ressurgimento daquelas grandes massas suspensas que conhecemos pelo nome de "cúpula" e que, segundo Eugenio D'Ors, lendo um trecho do velho Aloïs Riegl, remetiam à noção de uma monarquia forte (mas que também poderiam ser lidas como tentativa de gozo pela pretensão do retorno do pai à sua morada). Nesse mesmo tempo, à parte alguma ou outra nota obscura de Pitágoras, por exemplo, não se deixou de atestar o completo desaparecimento da sonoridade do passado. Confrontando-se com essa falta, no âmbito da formação da hierarquia das artes e dos fazeres, o engenho dos arquitetos parece ter se sobreposto ao dos músicos. Digo isso porque, enquanto os primeiros lembravam exatamente a relação da música com o tempo num tom meio insolente de um "assim que se faz, se desfaz", os músicos, por sua vez, na tentativa de suprir o monumento que lhes faltava, inventaram a opera - a obra -, cuja simples nominação remete mais à construção material do que a uma relação com os sons.

Por outro lado, talvez por uma ironia bem caprichosa, a música permaneceu como a única das "artes" que mantém nominalmente a inscrição genérica das Musas. Jean-Luc Nancy nos lembra que as Musas tomam o seu nome a partir de um radical que indica a excitação, a tensão viva que se eleva, se faz impaciência, desejo ou cólera, que arde por saber e fazer. A Musa, nesse sentido, anima, excita, coloca em movimento, e, além disso, está mais para a força do que para a forma (cf. Nancy, 2006, p. 19). E, tratando exatamente da questão do uso da linguagem no poema como um defrontar-se com a possibilidade do evento de linguagem e seu querer-dizer, Agamben nos fazia lembrar que "Musa é o nome que os gregos davam à experiência da inapreensibilidade do lugar originário da palavra poética", mas que, ainda assim, se mantém como estímulo imaginativo (cf. Agamben, 2008, p. 97).

Nesse intercâmbio entre som e palavra, entre voz e poema, dez anos antes de Siciliana, Murilo Mendes acolhia a 
música de uma maneira especial em alguns dos aforis-mos de $O$ Discípulo de Emaús: “ - A música pensa? Respondo: não há uma representação objetiva do mundo na música; há a contemplação das idéias que se equilibram enquanto número e ritmo" (Mendes, 1995, p. 881). Música e poesia parecem apontar para uma relação muito mais estreita do que se poderia acreditar. Defrontando-se ambas com um desejo tão grande elas nos imprimem no intelecto uma marca que vai para além do domínio da visão e indica a audição - "a gente não diz o que houve, mas o que ouve", nos termos de Oswald de Andrade. Isso talvez Murilo Mendes tenha aprendido ao confrontar-se com a figura de Polifemo, quem sabe, n'O claustro de Monreale, que, sem exigir tomar o lugar de Ulisses, não roga por vingança, nem pede nova morada, nova forma:

Confronto-me ao que foi antes de mim:

Em 1901 eu tinha

Seis milhões de anos.

Os que dormem sob as lápides,

Antecipando o futuro,

Viram o deus permanecer

Desde o princípio do tempo

Nas colunas geminadas.

(Mendes, 1995, p. 569)
Ou sob a ruína solitária das colunas d'O templo de Segesta que não sustentam nenhum teto ou cúpula:

Que música nos vem do número e da paz,

Que música nos vem do espaço organizado.

Propício ao ritmo é o deus do número,

$E$ pela seqüência do ritmo

A unidade do tempo se reconstrói.

\section{A Segesta com amor e lucidez eu vim Colher o que a morte não selou, \\ Sondando o oráculo que és tu mesmo, Tuas linhas de força e calma pedra. (Mendes, 1995, p. 566).}

Esse tempo, que não é nem apenas uma linha unidirecional e nem ao menos signo da impossibilidade de citar (e usar) o passado, está para o agora como a imago está para o retorno. É o que dizia Agamben, por exemplo, ao estudar um dos trechos em que Nietzsche tratava da vontade de potência e do eterno retorno usando um significante - Gleiche - que remetia à "mesma figura", à imagem do morto (Agamben, 2005, p. 334). Essa potência cuja origem é imemorial, que não é apenas ativa, ou seja, voltada para uma ação (ou uma formação), porque carrega consigo uma paixão, é afetada por ela - e, por isso mesmo, faz emergir uma força não mais restrita ao âmbito da representação objetiva do mundo. Algo disso 
estava, por exemplo, no ensaio sobre de Murilo Mendes sobre o eterno, publicado, em 1936, no quarto número da revista Lanterna Verde, quando lemos:

Muitos homens julgam que a idéia de eternidade reside num plano de mito, de ficção, ou que a eternidade é a vida do além-túmulo. Entretanto, a vida eterna começa neste mundo mesmo (Mendes, 1936, p. 45).

Esse eterno não se refere à incorruptibilidade da matéria, a matéria que dura, depois de que o mundo e os homens tenham sido purgados de suas faltas e falhas, mas sim aquilo que sempre perdura ou, em vocabulário benjaminiano, pervive: aquilo que surge e não se perde quando lemos (e ouvimos) na "siciliana" O eco de Siracusa, onde "o eco é forte, / Só ele se mantém / Mais vivo do que o / Augúrio original" (Mendes, 1995, p. 573).

\section{Referências:}

AGAMBEN, Giorgio. La potenza del pensiero. Vicenza: Neri Pozza, 2005. Stanze. La parola e il fantasma nella cultura occidentale. 3 ed. Turim: Einaudi, 2006.
Il linguaggio e la morte. Un seminario sul

luogo della negatività. 3 ed. Turim: Einaudi, 2008.

BENJAMIN, Walter. Origem do drama barroco alemão. Tradução de Sérgio Paulo Rouanet. São Paulo: Brasiliense, 1984.

MENDES, Murilo. Poesia completa e prosa. Rio de Janeiro: Nova Aguilar, 1995.

"O eterno nas letras brasileiras modernas",

in: Lanterna Verde, Rio de Janeiro, n. 4, nov. 1936, pp. 43-48.

NANCY, Jean-Luc. Le Muse. Tradução para o italiano de Chiara Tartarini. Reggio Emilia: 2006.

UNGARETTI, Giuseppe. "Prefácio a Siciliana, de Murilo Mendes". Tradução de A. A. Chiocchio, in: MENDES, Murilo. Poesia completa e prosa. Rio de Janeiro: Nova Aguilar, 1995, p. 38. 